\title{
PEROVSKITAS A BASE DE NÍQUEL E NIÓBIO COMO CATALISADORES PARA REFORMA A VAPOR DE METANO
}

\author{
JULIANA F. GONÇALVES ${ }^{1}$, MARIANA M.V.M. SOUZA ${ }^{1}$ \\ ${ }^{1}$ Escola de Química, Universidade Federal do Rio de Janeiro \\ E-mail para contato: mmattos@eq.ufrj.br
}

\begin{abstract}
RESUMO - O trabalho tem como objetivo estudar um catalisador para reforma a vapor do metano, que tenha alta atividade e resistência à formação de coque. Os catalisadores escolhidos são a base de perovskitas do tipo $\mathrm{LaNi}_{0,5} \mathrm{Nb}_{0,5} \mathrm{O}_{3}$ e foram sintetizados pelo método de combustão utilizando ácido cítrico, glicina e ureia como agentes combustíveis. Os resultados mostraram que a temperatura de calcinação da perovskita varia de acordo com o agente combustível utilizado. Amostras sintetizadas a partir do ácido cítrico, glicina e ureia foram calcinadas a 1000, 800 e $900{ }^{\circ} \mathrm{C}$, respectivamente, para uma boa formação de fase cristalina. A análise de TPR mostrou que a redução das perovskitas deve ser realizada a $1000{ }^{\circ} \mathrm{C}$ para que a fase ativa possa ser formada. Os catalisadores foram avaliados na reforma a vapor do metano em temperaturas entre 400 e $900{ }^{\circ} \mathrm{C}$ e acima de $800{ }^{\circ} \mathrm{C}$ conversões maiores que $90 \%$ foram obtidas com os três catalisadores testados.
\end{abstract}

\section{INTRODUÇÃO}

Atualmente, em virtude da grande demanda energética e esgotamento de recursos nãorenováveis, a humanidade tem buscado novas alternativas para o suprimento de suas necessidades energéticas. Além disso, há uma maior preocupação e conscientização ambiental, devido aos problemas gerados por ações antropogênicas, como efeito estufa e aumento do buraco na camada de ozônio.

Uma alternativa que tem sido considerada como a fonte de energia do futuro é o hidrogênio, devido à sua disponibilidade, flexibilidade de produção, grande quantidade de energia liberada quando comparada com o poder de combustão de um hidrocarboneto, por não ser tóxico e apresentar um menor potencial poluidor (Souza, 2009). O hidrogênio é uma das matérias-primas mais importantes para a síntese de produtos químicos, como o metanol e a amônia, e para diversos processos petroquímicos, como o hidrocraqueamento e hidrotratamento.

A rota mais utilizada para a obtenção de hidrogênio é a reforma a vapor de metano, que é um processo onde o metano reage com vapor d’água gerando gás de síntese, de acordo com a Equação 1:

$$
\mathrm{CH}_{4}+\mathrm{H}_{2} \mathrm{O} \rightarrow 3 \mathrm{H}_{2}+\mathrm{CO}
$$


Para a reforma a vapor, os catalisadores com metais nobres possuem maior atividade cataítica, alta seletividade para o gás de síntese e boa estabilidade. No entanto, o alto custo inviabiliza seu uso comercial. Para substituir os metais nobres, são utilizados catalisadores a base de metais de transição, embora sejam mais sensíveis à desativação pela deposição de coque. A atividade desses metais obedece a seguinte ordem: $\mathrm{Rh}, \mathrm{Ru}>\mathrm{Ir}>\mathrm{Ni}, \mathrm{Pt}, \mathrm{Pd}>\mathrm{Co}>\mathrm{Fe}, \mathrm{Cu}$ (Yin e Hong, 2009). O níquel é o catalisador mais usado em escala industrial por ser extremamente barato e suficientemente ativo, contudo seu comportamento catalítico é afetado diretamente pela sua grande sensibilidade à deposição de carbono e sinterização, quando utilizado em suportes. Esses dois fenômenos podem ser minimizados ao utilizar perovskitas como precursores de catalisadores de níquel.

Perovskitas são óxidos com fórmula geral $\mathrm{ABO}_{3}$, onde o sítio $\mathrm{A}$ é ocupado por cátions com número de coordenação 12 , geralmente por metais alcalinos ou alcalino-terrosos ou por terras raras, e é responsável pela estabilidade térmica. Já o sítio B é ocupado por cátions com número de coordenação 6, na maioria das vezes por metais de transição, e é responsável pelo desempenho catalítico (Tanaka e Misono, 2001).

O objetivo deste trabalho é preparar e caracterizar perovskitas do tipo $\mathrm{LaNi}_{0,5} \mathrm{Nb}_{0,5} \mathrm{O}_{3}$ pelo método de combustão a partir de diferentes agentes combustíveis, como o ácido cítrico, glicina e ureia. E identificar se esta perovskita é um catalisador promissor para a reforma a vapor do metano, com baixa formação de coque.

\section{MATERIAIS E MÉTODOS}

\subsection{Preparação e Caracterização dos Catalisadores}

Os reagentes utilizados foram o nitrato de lantânio, nitrato de níquel e oxalato amoniacal de nióbio e ácido cítrico, glicina e ureia, como agentes combustíveis. Para o método de combustão, os reagentes e os propelentes foram pesados na proporção adequada e adicionados em um cadinho de porcelana e, em seguida, aquecidos à $80^{\circ} \mathrm{C}$ sob agitação constante, até a formação de um gel. A mistura reacional foi então colocada em uma mufla, já previamente aquecida em $300{ }^{\circ} \mathrm{C}$, até a amostra sofrer ignição. Por fim, as amostras foram calcinadas na faixa de 600 a $1000{ }^{\circ} \mathrm{C}$ por $6 \mathrm{~h}$. Para uma comparação final dos resultados, foi sintetizada a perovskita $\mathrm{LaNiO}_{3}$ utilizando ureia como agente combustível.

A análise termogravimétrica foi realizada em uma termobalança da marca $T A$, modelo SDT Q600, em atmosfera oxidante. Para identificação das fases cristalinas, foram feitas análises em um difratômetro da marca Rigaku MiniFlex II. Com o intuito de determinar a área superficial específica BET, as amostras foram previamente secas até $300^{\circ} \mathrm{C}$ por $1 \mathrm{~h}$ sob vácuo e em seguida, isotermas de adsorção/dessorção de $\mathrm{N}_{2}$ a $-196{ }^{\circ} \mathrm{C}$ foram feitas. Outra técnica utilizada foi a redução à temperatura programada (TPR), onde a amostra era seca pela passagem de fluxo de argônio a $150{ }^{\circ} \mathrm{C}$ por 30 min e depois o fluxo foi trocado para uma mistura de $1,5 \%$ de $\mathrm{H}_{2} / \mathrm{Ar}$ para 
que os precursores óxidos fossem reduzidos por aquecimento até $1000{ }^{\circ} \mathrm{C}$.

\subsection{Testes Catalíticos}

As amostras foram reduzidas com $20 \% \mathrm{H}_{2} / \mathrm{N}_{2}$ a $1000{ }^{\circ} \mathrm{C}$ por $2 \mathrm{~h}$ e em seguida, iniciava-se a reação variando a temperatura de 400 a $900{ }^{\circ} \mathrm{C}$ com velocidade espacial de 1,2 x $10^{5} \mathrm{~mL} \cdot \mathrm{g}^{-1} \cdot \mathrm{h}^{-1}$ de $\mathrm{CH}_{4} / \mathrm{He}$. Os gases que saíam do reator foram analisados em um cromatógrafo a gás Shimadzu GC-2014 utilizando a coluna Carboxen 1010 e os detectores de condutividade térmica (TCD) e ionização de chama (FID), acoplado a um metanador. Depois de utilizados no teste de estabilidade, os catalisadores foram analisados por termogravimetria com o intuito de se obter informações quanto à deposição de coque.

\section{RESULTADOS E DISCUSSÕES}

\subsection{Caracterização dos Catalisadores}

Com o objetivo de determinar a temperatura máxima de chama e o tempo de ignição relacionados às reações de combustão, foi feito, através de um termopar inserido no meio reacional, o acompanhamento da temperatura do sistema de combustão em função do tempo de reação. A Figura 1 (a) mostra o comportamento da temperatura da amostra com o passar do tempo, utilizando diferentes combustíveis.

(a)

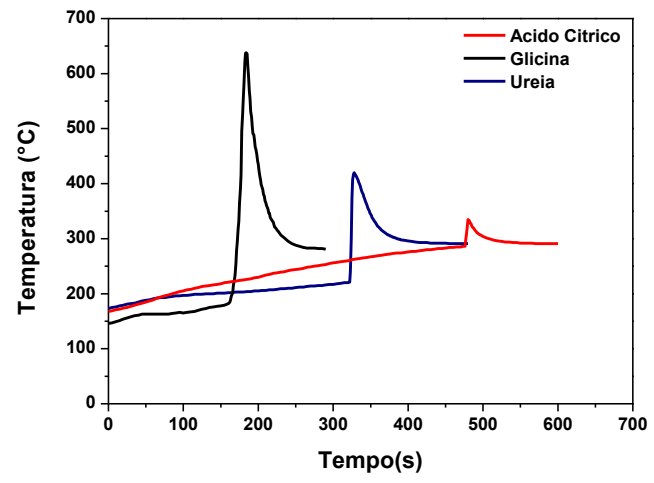

(b)

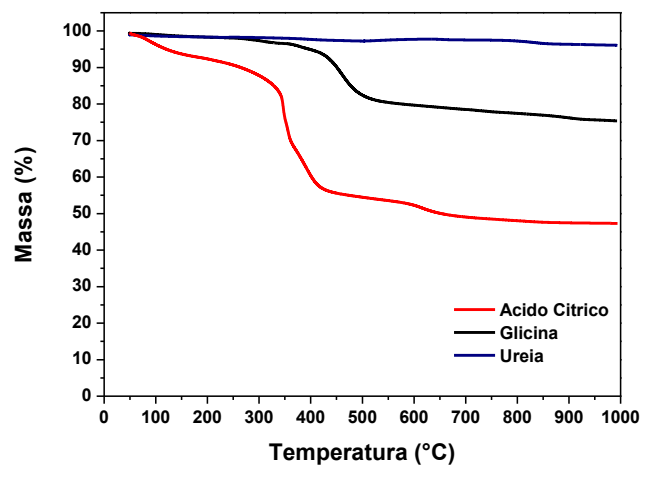

Figura 1 - Medidas da temperatura de chama (a) e curvas ATG (b) das amostras sintetizadas com ácido cítrico, glicina e ureia. 


\section{9 a 22 de outubro de 2014 \\ Florianópolis/SC}

A amostra sintetizada com ácido cítrico apresentou um maior tempo de ignição e a menor temperatura máxima de chama, sugerindo uma combustão incompleta, já que não houve energia suficiente para transformar os reagentes completamente, como visto por Silva et al. (2012a). O material final fica com grande quantidade de resíduo orgânico, devido à combustão incompleta, que pode ser explicada por seu baixo calor de combustão. A amostra com glicina apresentou a mais elevada temperatura máxima de chama e menor tempo de ignição, o que favorece a formação de estados aglomerados e grande quantidade de resíduos orgânicos, consequentemente má formação de fase. Essa combustão violenta que ocorre com a glicina pode ser explicada por seu elevado calor de combustão. Esse mesmo comportamento foi também observado por Silva et al. (2012b).

Já a amostra com ureia apresentou temperatura máxima de chama e tempo de ignição intermediários ao comparar com as outras duas amostras, perfil típico de uma amostra com combustão completa. Como sua ignição não se deu de forma violenta e permitiu uma maior formação de gases, o material final apresenta boa cristalinidade, alta porosidade e menos resíduo orgânico. Essa observação é corroborada pelo valor do calor de combustão deste agente combustível. Como não é um valor elevado, sua combustão não é violenta e consequentemente, não alcança elevadas temperaturas de chama.

A Figura 1 (b) mostra a perda de massa para as amostras sintetizadas com cada agente combustível antes de serem calcinadas. Nota-se que as três curvas de ATG são bem distintas, enquanto a amostra com ácido cítrico perde aproximadamente 50\% de sua massa, a amostra com ureia perde menos de 5\%, semelhantes aos resultados encontrados por Silva et al. (2012a). Na curva do ácido cítrico, a primeira etapa de decomposição é observada até $300{ }^{\circ} \mathrm{C}$ aproximadamente, que é atribuída à perda de água e voláteis. A segunda etapa, entre 300 e 650 ${ }^{\circ} \mathrm{C}$, pode ser oriunda da decomposição dos resíduos orgânicos que não foram queimados totalmente durante a síntese. Na curva da glicina, há apenas uma etapa de decomposição que está entre 400 e $500{ }^{\circ} \mathrm{C}$, que se atribui à decomposição de resíduos orgânicos, com perda de aproximadamente $25 \%$ de sua massa. Já na curva da ureia, praticamente não há perda de massa significativa.

Todas as amostras foram calcinadas em diversas temperaturas, na faixa de 600 a $1000{ }^{\circ} \mathrm{C}$, com o intuito de se obter a menor temperatura de calcinação que permita a formação de uma amostra cristalina, conforme é mostrado na Figura 2. Para a amostra sintetizada com o ácido cítrico como agente combustível, uma fase cristalina bem definida só foi obtida a $1000{ }^{\circ} \mathrm{C}$. Já para a amostra sintetizada com a glicina, a menor temperatura de calcinação que forma fase cristalina é a $800{ }^{\circ} \mathrm{C}$. E é na temperatura de $900{ }^{\circ} \mathrm{C}$ que a amostra sintetizada com a ureia forma uma boa fase cristalina. Sendo assim, as temperaturas mínimas de calcinação para as amostras sintetizadas com ácido cítrico, glicina e ureia foram, respectivamente, 1000, 800 e $900{ }^{\circ} \mathrm{C}$, para uma boa formação de fase cristalina. De acordo com essas temperaturas, as seguintes nomenclaturas foram adotadas: AC 1000, GLI 800 e UR 900.

Sabendo a temperatura mínima de calcinação para cada amostra, o próximo passo foi identificar quais compostos estão presentes. Foram realizadas análises qualitativas para cada uma 
das três amostras a partir de seus respectivos difratogramas, como mostra a Figura 2. Em nenhum deles, a perovskita $\mathrm{LaNi}_{0,5} \mathrm{Nb}_{0,5} \mathrm{O}_{3}$ foi identificada, porque não há ficha cristalográfica para este composto.

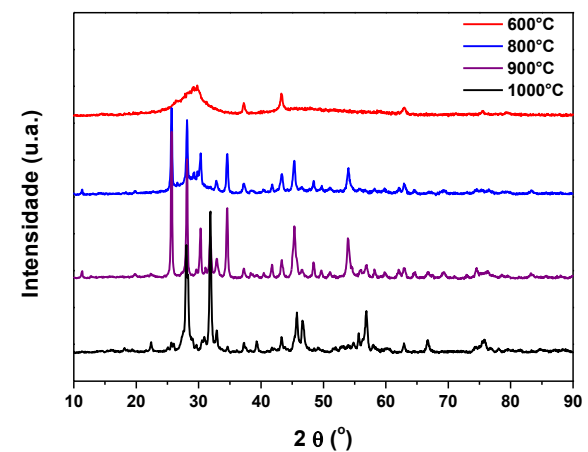

(a)

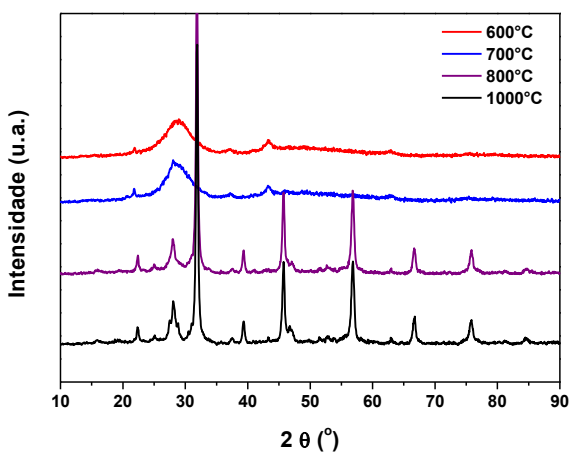

(b)

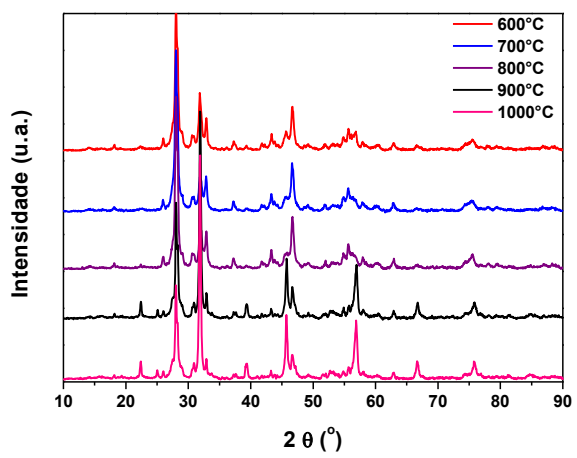

(d)
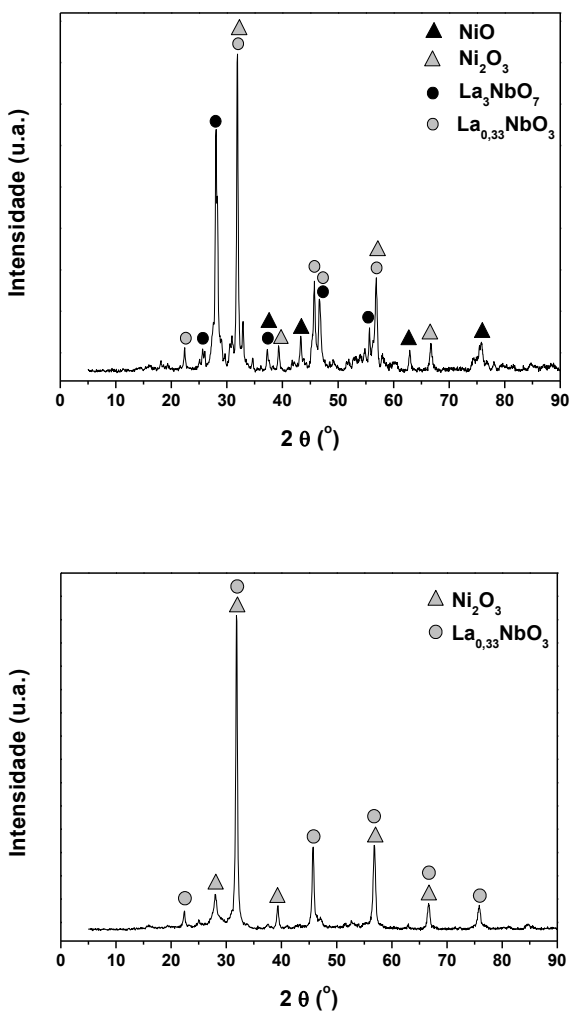

(e)

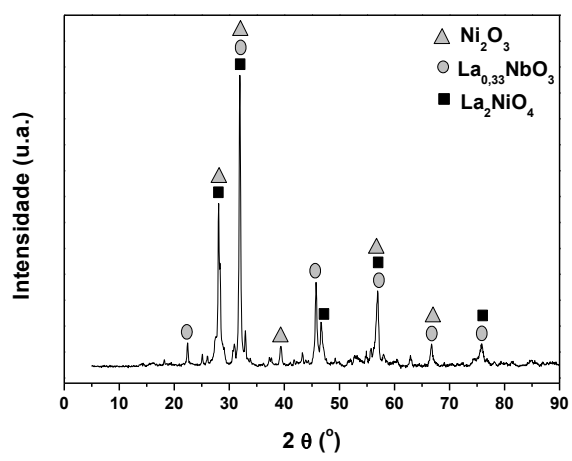

(c)

Figura 2 - Difratogramas das amostras sintetizadas com ácido cítrico (a), glicina (b) e ureia (c) em várias temperaturas de calcinação e das amostras com ácido cítrico calcinada a $1000{ }^{\circ} \mathrm{C}(\mathrm{d})$, glicina calcinada a $800^{\circ} \mathrm{C}$ (e) e ureia calcinada a $900^{\circ} \mathrm{C}$ (f). 
As amostras sintetizadas com o ácido cítrico e calcinadas a $1000{ }^{\circ} \mathrm{C}$ têm em sua composição o $\mathrm{NiO}$ (JCPDS 47-1049), $\mathrm{Ni}_{2} \mathrm{O}_{3}$ (JCPDS 14-0481), $\mathrm{La}_{3} \mathrm{NbO}_{7}$ (JCPDS 36-0671) e $\mathrm{La}_{0,33} \mathrm{NbO}_{3}$ (JCPDS 36-0126). Já as amostras sintetizadas com a glicina e calcinadas a $800{ }^{\circ} \mathrm{C}$ têm em sua composição o $\mathrm{Ni}_{2} \mathrm{O}_{3}$ e $\mathrm{La}_{0,33} \mathrm{NbO}_{3}$. E as amostras sintetizadas com a ureia e calcinadas a $900{ }^{\circ} \mathrm{C}$ têm em sua composição o $\mathrm{Ni}_{2} \mathrm{O}_{3}, \mathrm{La}_{2} \mathrm{NiO}_{4}$ (JCPDS 34-0984) e $\mathrm{La}_{0,33} \mathrm{NbO}_{3}$.

Os valores de área específica BET obtidos para as amostras AC 1000, GLI 800 e UR 900 são, respectivamente, $3.3,3.0$ e $2.2 \mathrm{~m}^{2} / \mathrm{g}$. Tais valores estão coerentes, uma vez que a literatura aborda que em geral perovskitas possuem baixas áreas superficiais, menores que $10 \mathrm{~m}^{2} / \mathrm{g}$ (Silva et al., 2013).

A análise de TPR é de grande importância, pois indica em que temperatura se deve reduzir o catalisador para que este esteja na forma ativa ( $\mathrm{Ni}$ metálico) para ser utilizado nas reações. A Figura 3 mostra os perfis de redução para as amostras sintetizadas.

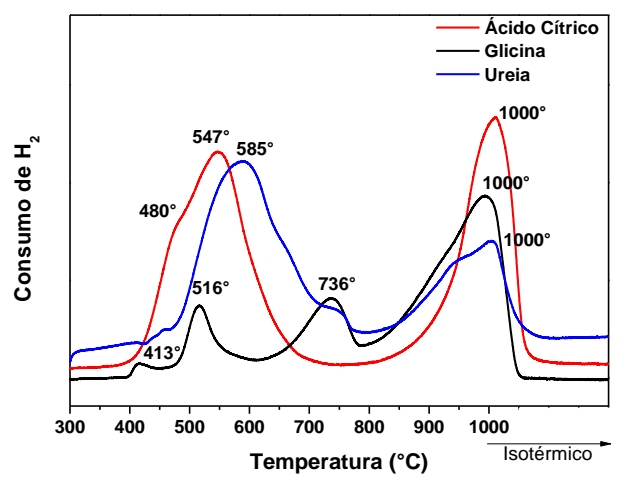

Figura 3 - Perfis de redução à temperatura programada das amostras sintetizadas.

Os picos a $480{ }^{\circ} \mathrm{C}$ e a $413{ }^{\circ} \mathrm{C}$ podem estar associados à redução das espécies $\mathrm{Ni}^{3+}$ a Ni ${ }^{2+}$. Já os picos a $547{ }^{\circ} \mathrm{C}$ do ácido cítrico, $516^{\circ} \mathrm{C}$ e $585{ }^{\circ} \mathrm{C}$ são característicos da redução do $\mathrm{Ni}^{2+}$ a níquel metálico $\left(\mathrm{Ni}^{\circ}\right)$ ( Li et al., 2004). Na amostra sintetizada com glicina aparece um pico a 736 ${ }^{\circ} \mathrm{C}$ que pode estar associado a uma redução do níquel que tem interação mais forte com o suporte, no caso a nióbia (Jasik et al., 2005). Já o pico de $1000{ }^{\circ} \mathrm{C}$ pode ser característico da redução parcial da nióbia, que ocorre em altas temperaturas.

\subsection{Teste Catalítico}

As conversões de metano e razões $\mathrm{H}_{2} / \mathrm{CO}$ para o intervalo de temperatura estudado são apresentadas na Figura 4 (a). Os catalisadores obtiveram resultados próximos em todo intervalo de temperatura estudado, mas foi o catalisador sintetizado com ureia que obteve maior conversão de metano, $91,4 \%$ a $900{ }^{\circ} \mathrm{C}$. A perovskita $\mathrm{LaNiO}_{3}$ apresentou perfil semelhante, o que sugere que a adição de nióbio não implica em um aumento efetivo na conversão de metano. 


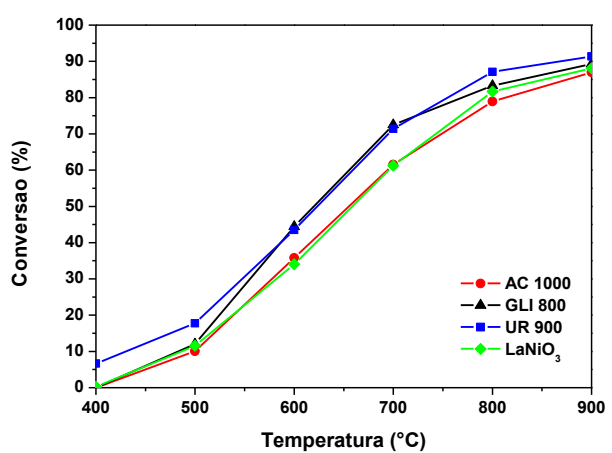

(a) (b)

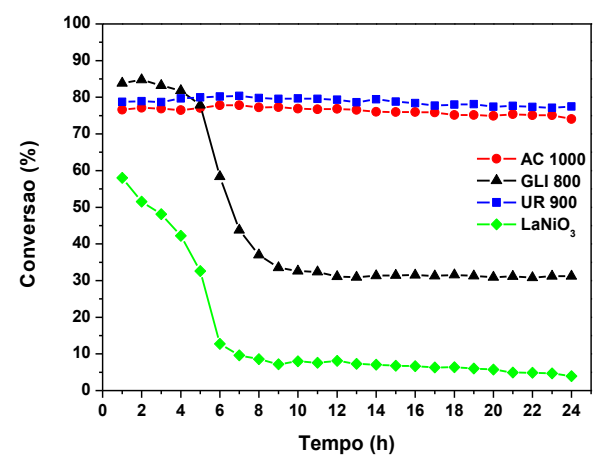

Figura 4 - Conversão de metano entre $400-900{ }^{\circ} \mathrm{C}$ (a) e no teste estabilidade a $700{ }^{\circ} \mathrm{C}$ (b) para os quatros catalisadores testados.

Depois de analisar as conversões para cada catalisador, foi escolhida a temperatura de 700 ${ }^{\circ} \mathrm{C}$ para a realização do teste de estabilidade, cujos resultados estão na Figura 4 (b). Os catalisadores sintetizados com ácido cítrico e ureia não sofrem desativação durante o período de teste, 24 h. No entanto, o mesmo comportamento não é visto para o catalisador sintetizado com glicina, cujo valor de conversão de metano diminuiu de 83,3\% para 31,2\% após as $24 \mathrm{~h}$ de teste. $\mathrm{E} \mathrm{o} \mathrm{LaNiO}_{3}$ teve sua conversão reduzida de $58 \%$ a $4 \%$, mostrando que essa perovskita não dopada com nióbio desativou por completo durante o teste.

Após o teste de estabilidade, os catalisadores utilizados foram analisados por termogravimetria para verificar a deposição de coque. Notou-se que os catalisadores preparados com ácido cítrico e ureia não tiveram deposição de coque, pois se houvesse, a amostra perderia massa, uma vez que em $1000{ }^{\circ} \mathrm{C}$ todo o coque já teria sido oxidado. Já o catalisador preparado com glicina perdeu aproximadamente $80 \%$ de sua massa, associado ao coque depositado durante o teste de estabilidade.

\section{CONCLUSÕES}

A amostra sintetizada com a ureia como propelente foi a única obteve combustão completa, já que se deu de forma lenta, não alcançou alta temperatura de chama e pela análise termogravimétrica, constatou-se que havia poucos resíduos orgânicos. Para uma boa formação de fase, as perovskitas sintetizadas com ácido cítrico, glicina e ureia devem ser calcinadas a 1000, 800 e $900{ }^{\circ} \mathrm{C}$, respectivamente. Foi constatado que para a redução completa do níquel, a temperatura mínima a ser usada é de $736^{\circ} \mathrm{C}$.

Quanto aos testes catalíticos, é possível afirmar que os três catalisadores possuem atividades semelhantes, já que apresentaram conversões similares nas mesmas temperaturas. Os testes de estabilidade a $700{ }^{\circ} \mathrm{C}$ mostraram que os catalisadores sintetizados com ácido cítrico e 
ureia não sofreram desativação por $24 \mathrm{~h}$, uma vez que os valores de conversão de metano se mantiveram estáveis. As perovskitas a base de níquel e nióbio se mostraram muito mais estáveis que o niquelato de lantânio. Dessa forma, pode-se concluir que a adição de nióbio permite uma maior estabilidade química e resistência à formação de coque. Por fim, as perovskitas a base de níquel e nióbio mostraram ser precursores promissores para catalisadores de reforma a vapor de metano. E ao dopá-las, o agente combustível mais indicado para a síntese é a ureia, já que essa apresentou combustão completa, maior grau de redução, maior valor de conversão de metano e não desativou durante o teste de estabilidade.

\section{REFERÊNCIAS}

JASIK, A.; WOJCIESZAK, R.; MONTEVERDI, S.; ZIOLEK, M.; BETTAHAR, M.M.; 2005; "Study of nickel catalysts supported on $\mathrm{Al}_{2} \mathrm{O}_{3}, \mathrm{SiO}_{2}$ or $\mathrm{Nb}_{2} \mathrm{O}_{5}$ oxides"; J. Mol. Catal. A: Chem.; v. 242; p. 81-90.

LI, J.; LU, G.; LI, K.; WANG, W.; 2004; “Active $\mathrm{Nb}_{2} \mathrm{O}_{5}$-supported nickel and nickel-copper catalysts for methane decomposition to hydrogen and filamentous carbon"; J. Mol. Catal. A: Chem.; v. 221; p. 105-112.

SILVA, A.A.A.; DA COSTA, L.O.O.; MATTOS, L.V.; NORONHA, F.B.; 2013; "The study of the performance of Ni-based catalysts obtained from $\mathrm{LaNiO}_{3}$ perovskite-type oxides synthesized by the combustion method for the production of hydrogen by reforming of ethanol"; Catal. Today; v. 213; p. 25-32.

SILVA; A.L.A; CASTRO, G.G.G.; SOUZA, M.M.V.M.; 2012(a); "Synthesis of Sr-doped $\mathrm{LaCrO}_{3}$ powders by combustion method: influence of the fuel agent"; J. Therm. Anal. Calorim.; v. 109; Issue 1; p. 33-38.

SILVA, A.L.A.; CONCEIÇÃO, L.; ROCCO, A.M.; SOUZA, M.M.V.M.; 2012 (b); "Synthesis of Sr-doped $\mathrm{LaMnO}_{3}$ and $\mathrm{LaCrO}_{3}$ powders by combustion method: structural characterization and thermodynamic evaluation"; Cerâmica; v. 58; p. 521-528.

SOUZA, M.M.V.M.; Tecnologia do Hidrogênio; Editora Synergia; Rio de Janeiro; 2009.

TANAKA, H.; MISONO, M.; 2001; “Advances in designing perovskite catalysts"; Curr. Opin. Solid State Mater. Sci.; v.5; p. 381-387.

YIN, X.; HONG, L.; 2009; "Partial oxidation of methane to syngas over the catalyst derived from double perovskite $\left(\mathrm{La}_{0,5} \mathrm{Sr}_{0,5}\right)_{2} \mathrm{FeNiO}_{6-\delta}$; Appl. Catal. A: Gen.; v.371; p.153-160. 